\title{
Training quality for Vietnamese cadres and civil servants in the context of international integration
}

\author{
Thi Hoa Nguyen ${ }^{1, *}$ \\ ${ }^{1}$ Thu Dau Mot University, No 6, Tran Van On str, Phu Hoa ward, Thu Dau Mot city, Binh Duong \\ province, 820900 , Vietnam
}

\begin{abstract}
In the current context, the training for cadres and civil servants is crucial to the operations of the civil service system. However, it is influenced by many factors, affecting its effectiveness in practice. This article makes mention of factors affecting the quality of training and retraining for cadres and civil servants, such as policy institution, management, inspection, supervision and curriculum, etc., Therefore, identifying factors affecting the training and retraining is to find suitable solutions, making an important contribution to improve the capacity of cadres and public servants as well as the effectiveness of public service.
\end{abstract}

\section{Introduction}

Cadres and civil servants play a decisive role in the effectiveness and efficiency of state management. In recent years, due to the implementation of administrative reform, renewal and quality improvement of the contingent of state cadres and civil servants have been paid particular attention. Hence, their capacity has increasing to meet social life's development needs.

We live in times at a dizzying rate of change, which is the era of information technology explosion. The explosion has a substantial impact on the perception, thinking, and working method of cadres and civil servants. Therefore, it also requires state agencies, in general, to equip, improve their qualifications, and update knowledge for cadres and civil servants to complete their tasks. Therefore, the need for training becomes more urgent than ever. The overall goal of training and developing the cadres and civil servants is to make the best use of existing human resources and improve its efficiency by enhancing cadres and civil servants' professional qualifications and skills.

The refresher training (retraining) meets the organization's current needs and also increases the self-confidence, self-assertion and morale of the contingent of cadres and civil servants. Simultaneously, this is also a prerequisite to increasing this organization's prestige and competitiveness with other organizations. Moreover, for government agencies, the retraining for cadres and civil servants is an urgent and most important task because it plays a particularly important role in improving operations public service activities of all government levels.

${ }^{*}$ Corresponding author: hoant.khql@tdmu.edu.vn 
Moreover, the need for administrative personnel retraining has also derived from the people's increasing demands in public service execution. To many countries around the world, it is also the trend to enhance the role of service which stems from the primary function of the state in managing all aspects of social life.

\section{Materials and methods}

We use he comparison and analysis methods to analyze and compares mechanism management, which related to implementation of administrative reform, renewal and quality improvement of the contingent of state cadres and civil servants in Vietnam today. Based on legal, public policies and management approach, this paper makes mention of factors affecting the quality of training and retraining for cadres and civil servants, such as policy institution, management, inspection, supervision and curriculum, etc., Therefore, identifying factors affecting the training and retraining is to find suitable solutions, making an important contribution to improve the capacity of cadres and public servants as well as the effectiveness of public service

\section{Results}

\subsection{Some factors affect the quality of cadres and civil servants' training in the international integration context}

The training and retraining to cadres and civil servants is the process of imparting professional knowledge and skills in various forms, following the requirements of handling the quality of assigned work. The capacity of public officials depends heavily on the amount of professional knowledge that has been equipped. Therefore, the quality of training and retraining dramatically affects the contingent of cadres and civil servants. The training and retraining of cadres and civil servants may look superficially simple, whereas they are quite complicated when researching and analyzing in-depth.

Training for cadres and civil servants has a difference from national education. National education can provide human intellectual resources for society, including human resources for state management activities. On the contrary, the training for cadres and civil servants must be based on the Law on cadres and civil servants. In other words, it only has been conducting within human resources for state management and related to the scope of state management.

When it comes to the factors influencing the training and retraining of cadres and civil servants, it is mentioned in the following elements:

The institutional policy is the legal framework showing all the Party and the State's views and procedures on the training and retraining for cadres and civil servants. An appropriate institutional policy creates conditions for cadres and civil servants to feel secure working and learning to improve their professional qualifications. The inappropriate policy regime, in contrast, even has caused superficiality, lack of responsibility in learning to strengthen cadres, and civil servants' professional capabilities. Therefore, the institutional policy is the factors that significantly affect the promotion of each cadre and civil servants' capacity and their training and fostering.

The institutional policy of the training and retraining for cadres and civil servants still has many shortcomings and limitations. Many documents issued are not timely or revised slowly, affecting training and retraining for cadres and civil servants. Therefore, it is necessary to plan based on the practical training needs and retraining of cadres and civil servants. The policy must show the priority for training and retraining to perfect civil 
servants' rank and titles. Besides, the promulgation of institutional policy needs to base on the criteria of ranks and titles of cadres and civil servants to match their positions' training requirements. Therefore, it is necessary to institutionalize training and retraining orientation, decentralization on training and retraining, increasing autonomy for training institutions, and promulgating a list of needed skills for titles, groups of civil servants. Besides, it is essential to have a separate regime for trainers, trainees, and institutions because the training does not have to train by degrees according to training majors.

Hence, for the quality of training and retraining to be effective, it is necessary to synchronize the planning and promulgation of solutions on institutional and policy. The Party and State's orienting views and basic principles on fostering cadres and civil servants in the current period need to study and promulgate programs and plans for training and retraining cadres, specific civil servants suitable to local characteristics and conditions. Specifically:

Firstly, title standards should be issued for each specific and precise position. Requirements for standards include qualifications that have been trained (culture, expertise, politics) and ethical qualities, work experience, age, etc. Title standards must be based on the results of careful and rigorous research of the job description analysis process and the virtue of practical experience to set the right criteria for job requirements.

Secondly, it is essential to study, amend, supplement, or issue new documents on the training to suit their job requirements and each locality's reality. Moreover, research and adjust institutional policy need to encourage cadres and civil servants to improve their knowledge and public service skills to improve the administration's service quality.

Examining, supervising, and managing the training for cadres and civil servants significantly improves the civil service system's quality and efficiency. On that basis, the management levels will create a management mechanism and strengthen the inspection and supervision training activities in a reasonable way to promote their real capacity.

The purpose of the management, inspection, and supervision of training and fostering is to improve the quality and capacity of the contingent of cadres and civil servants. From there, new and positive factors will be discovered while overcoming weaknesses and shortcomings, contributing to improving the capacity of cadres and civil servants in the context of international integration.

From there, these activities will assist the authorities at all levels to consolidate the current training system. It also contributes to improving the organization's operations' quality and efficiency, especially exploiting the capacity of the contingent of cadres and civil servants.

To increase the efficiency of these activities, authorities need to pay attention to inspection and supervision activities. It is also necessary to build a team of inspection and supervision that are enough moral and capacity to perform this critical mission. Talking about cadres' mission, President Ho Chi Minh pointed out that: "... cadres are the root cause of all jobs, successes or failures are due to good or poor staff" ; The Party's Resolution 03-NQ/TW, term VIII on cadres strategy in the period of national industrialization and modernization also determined: "The cadres are the decisive factor for the success or failure of the revolution, associated with the Party's destiny, of the country and the regime, is a key step in the work of Party building" . Therefore, the inspection and supervision of training and retraining activities for cadres and civil servants are crucial in improving cadres and civil servants. If it is done well, the capacity and efficiency of the civil service system will be enhanced. Conversely, it will inhibit and adversely affect the role of the State in the performance of public service at all levels.

Awareness of cadres and civil servants to the training and retraining is a fundamental and decisive factor in training and retraining activities. Right understanding is the premise, a guideline for the right and scientific actions, and vice versa. If each of them recognizes 
the role and importance of training, they will have a motivation to improve their own qualifications, knowledge, skills, and working methods; If they understand that learning is to serve themselves in improving the quality of public service activities, they will have a sense of self-training, knowledge improvement, inquiring, participating in training and retraining courses in a positive, passionate and effective way. With the right awareness of cadres and civil servants, they will have a positive attitude when participating in training courses and training, thereby achieving good results. Simultaneously, the organization's training activities have achieved the goals and proposed plans.

On the contrary, misperceptions will make them indifferent when participating in training courses, causing waste in training. In reality, we are spending a lot of time and money on each training course for cadres and civil servants, but as a result, their capacity and working attitude have not been improved much. The goals and results of the refresher training will not be as expected. It implicitly led to the training and retraining of mere extremely formality but not high quality. A number of cadres and civil servants have participated in training courses to supplement diplomas or certificates instead of their dedication and passion. Hence, their knowledge is deficient and has not brought their capacity into full play to implement the work. .

Besides, their organization's attention also dramatically affects the quality of training and retraining. The unit's views of managing and using cadres and civil servants play a particularly important role in training and retraining. This role is reflected in the sights on policies, remuneration, coordination in the implementation process, and the unit's resources, thereby affecting the unit's resources devoted to training staff, public servants. Departments always concerned with training will have appropriate policies and regimes for training cadres and civil servants. Priority, encouragement and incentive policies help promote training activities, promoting cadres and civil servants to actively participate in learning to improve professional qualifications, working capacity, and vice versa. We all know humans as superior conscious beings whose every activity has a purpose and always has a corresponding drive to promote actions to satisfy matter and chimpanzees' needs. Therefore, regularly pay attention to material benefits (accommodation, travel, tuition fees, etc.,) and spiritual blessings (praise and reward when achieving high learning process results). Having appropriate remuneration policies is a handy tool in promoting the effectiveness of training activities. For agencies with limited financial resources, with insufficient funds for physical encouragement, the form of spiritual reward and recognition also enables excellent value. Consistent use of encouragement measures creates motivation for cadres and civil servants to study and improve professional qualifications and working capacity. That is one of the factors contributing to improving the quality of training and retraining activities. Besides, the coordination between the management cadres and civil servants and the training units also plays a vital role in the training process. It affects whether the unit's training units are suitable for the training program or not, thereby affecting training quality. This coordination is also reflected in the management unit, using cadres and civil servants to create favorable conditions for them to participate in training.

Physical facilities such as schools, classes, teaching and learning equipment, tools, etc., are essential factors that also can give impact positively and negatively on the training process. Adequate facilities are favorable conditions for training activities. Conversely, inadequate physical facilities have some adverse effect on students' interest to learn as well as training activities, even can not to carry out retraining activities. Hence, the institute for training and retraining for cadres and civil servants is a place to organize training courses with good condition and modern equipments, and to update and supply knowledge and skills of public service activities. It must ensure minimum standards of a modern educational institution such as a spacious campus, hall, classroom, campus, modern teaching equipment, etc. 
The training and retraining institutions are currently scattered inadequate, incapacity, while training organization is wasteful. In general, the classrooms' usable capacity is not high. The lecturers' actual teaching hours are low, and the existing facilities are too modest compared to the competitive training and retraining institutions in the area. The classrooms are lack of physical facilities and a motivating learning environment which have only school-style furniture, writing board, and amplifiers with speakers and microphones. Therefore, to improve the quality of training and retraining of cadres and civil servants at training institutions, it is necessary to invest and build modern facilities and teaching equipment to serve the teaching, studying and scientific research activities.

The training budget is a decisive factor in the number of cadres and civil servants. The expense of training is usually provided by government budget if they are cadres and civil servants or by public non-business units if they are officials. It could be the trainees' contributions if they belong to a public non-business with partial financial autonomy or support from programs and projects. Having good fund management will vigorously promote training and retraining. Thus, the state needs to invest money in training and retraining to improve its quality. For many years, the Party and State have seen the importance of education and training, considering it as a "top national policy" task. It is necessary to have a public finance adequate investment focusing on human capital to create a driving force for development.

Investment in training and retraining for civil servants is a factor influencing the quality and efficiency of public service delivery. It is necessary to identify investment objectives timely and adequately in each stage. Increasing investment for these activities to support the number of cadres and civil servants who still "owe" the standard of the rank and grade, those newly recruited or haven't met the requirements, especially in the international integration process.

Although the financial source and the mechanism using the state budget for the training and retraining cadres and civil servants are regularly strengthened, supplemented and modified, some regulations are still too tight and unreasonable. The budgetary allocated for training and retraining activities has steadily increased but remains at a low level, unable to meet the increasing needs, especially in the innovation of training and retraining methods. It requires fewer trainees in each course while the costs for teaching and learning equipment are higher. The cost prescribed in Circular No. 139/2010 / TT-BTC dated September 21, 2010, of the Ministry of Finance, is too low and no longer suitable for the current social reality, especially for the teaching force. The regime for cadres and civil servants to go to school, especially in remote and mountainous areas, is not guaranteed and encouraged. Therefore, it is necessary to have appropriate financial solutions for the current training to improve its quality and efficiency.

The human resource of training institutions are a decisive factor in training and retraining activities for cadres and civil servants. Human resources include leaders, trainers, supporters, and training managers. Specifically:

Leadership team with specific policies help the training process actualized. Its efficiency depends a lot on the views and policies of leaders and managers.

Lecturers are a critical factor in the process of training and retraining for cadres and civil servants. Highly qualified lecturers are a positive factor affecting training and retraining quality. Teachers not only must be knowledgeable, skilled in their teaching fields but have in-depth knowledge and proficiency. Hence, it is required to have regulations on organization on using and training regularly for adjunct lecturers of the institutions.

The individual working as a supporter and manager in the training courses are in charge of performing partial works linking the steps into a complete training process. The quality of training also depends on the capacity and working style of this team.

Therefore, it can be seen that the process of training and retraining cadres and civil 
servants depends a lot on the qualifications and capabilities of the lecturers, leaders and support staff who join directly on managing and teaching for cadres and civil servants on this process. To achieve the training and retraining objectives, plans and programs, it is required to have a good organization and management, as follows:

- Manage teaching and learning processes of teachers and students;

- Manage organizational operations, human resources;

- Manage resources and materials for training and retraining;

- Manage training and retraining environment;

On the modern teaching method, it is claimed that "In the training and retraining process, the teacher plays a decisive role in the teaching process and learner-centered to promote effective learning of knowledge, skills and attitude. There is no educational system that can reach beyond the level of the teachers working in that system. The teachers impart knowledge and lead, organize and control the learners' cognitive activities, and also be instructors and mentors for the learner". The characteristics of learners are that they are both the subject and the "priority" object of the training retraining process. Thus, it can be affirmed that lecturers in training and retraining institutions are essential in enhancing training and retraining quality. Its quality and effectiveness depend primarily on the lecturers.

The working environment is a combination of human factors and material means to achieve productivity, quality, and efficiency. The working environment is one of the factors affecting the development of cadres and civil servants and deciding the performance of the agency or organization. A healthy and positive workplace environment is a great way to encourage them to work and continuously improve their professional qualifications. On the contrary, an ineffective working environment and lack of solidarity will create the inertia and absence of consensus and solidarity of cadres and civil servants and discourage their learning process.

The working environment includes material and nonmaterial aspects. The material working environment refers to physical conditions such as light, equipment, and machines used in the office. The nonmaterial working environment, in contrast, consists of the psychological atmosphere in the classroom, organizational culture, and traditions. Those aspects are linked to create the office's working environment.

In the current civil service system, the work environment plays a crucial role in the performance and development of cadres and civil servants. An ideal working environment is an essential element to attract and retain talents as well as give them a boost to enhance their level. In other words, an unhealthy working environment will limit their capabilities and discourage them from improving their professional skills and qualifications. The latter is often a result of restrictions in place that may impact the efficiency of training and retraining for cadres and civil servants.

The curriculum has a significant influence on the training and retraining results in the current integration context. The instability and regularly updating requisition are the most prominent training programs' training courses or textbooks, training materials. It makes an obstacle to training and retraining activities because it requires a content renewal to meet the learners' audience and practical needs.

Hence, the curriculum needs to toward practical issues raised from the public service implementation and improve administrative skills. The training and retraining for profession, expertise, and skills aims to ensure consistency in administrative agencies' operation, especially the awareness and responsibility in the problem-solving and the citizen and business engagement. It is necessary to implement pre-training on public service and on-duty public service annual and pre-appointment..

The curriculum must ensure sufficient knowledge and professional skills to meet civil service requirements for cadres and civil servants in the integration context. The curriculum 
should cover basic knowledge to equip learners with a dialectical materialism worldview, the scientific revolution's methodology, improve theoretical thinking, organizational skills, practical reviews, and apply the knowledge creatively and effectively.

For the cadres and civil servants who are the leaders and managers, the curriculum should focus on building the leadership and management science-centered leadership skills, the art of leadership to equip them with essential knowledge and skills in administration. It is vital to link theoretical research to practice, update new undertakings and policies and practical experience in dealing with specific situations that occur at the grassroots level to improve the capacity and qualifications of cadres and civil servants.

To bring the training and retraining into play, the Decree 36/2013 / ND-CP on job positions and structures of civil servant ranks must be implemented carefully and effectively by agencies and organizations to clearly define the functions, structure and criteria of civil servant titles in each governmental agency to serve as a basis for the recruitment and assignment. Building titles, standards, job positions, and civil service employment structure is a foundation for making specific, feasible and practical plans for the training and retraining, ensuring the training requirements according to civil servants' titles ranks and associated with the practice. Developing the curriculum that meets the practical needs should be clearly defined what learners need to achieve after completing the course, such as updating information, fostering knowledge and improving professional skills. It also allows cadres and civil servants to choose appropriate and practical programs according to their own job needs, thereby getting motivated and with a positive and serious study attitude.

\section{Conclusion}

In conclusion, to create practical training progress contributing to the development of cadres and civil servants, meeting the requirements of the renovation period, ensuring completion, it necessitates comprehensive solutions to the factors affecting the training and retraining process mentioned above. Besides, it is necessary to make the assessment, planning, arrangement and use cadres and civil servants. The inspection and evaluation of the quality of post-trained cadres and civil servants, surveying cadres and civil servants' real situation and identifying training and retraining needs for proper arrangement and planning direction should implement annually. These stages are related to each other and to training plan so as to meet the requirements and objectives. Therefore, training and retraining cadres and civil servants are always urgent and vital issues for the authorities at all levels. Improving the quality of training is essential to enhance cadres and civil servants' capacity and efficiency. Since then, it has deeply affirmed the views of the Party and State in building a rule of the law state that the government of the people, by the people, for the people in each Vietnamese people.

\section{References}

1. Do Muoi, Promoting the Renewal of Socialism (National Political Publishing House, Ha Noi, 1996)

2. Ho Chi Minh, Full set, Book 5, 6, 10 (National Political Publishing House, Ha Noi, 1995)

3. Vietnam Law on Cadres and Civil Servants (2008)

4. Luong Trong Yen, Bui The Vinh, The Asean's administrative model (National Political Publishing House, Ha Noi, 2004) 
5. Nguyen Phu Trong, Tran Xuan Sam, The scientific justification for improving the quality of the staff in the period of accelerating industrialization and modernization (National Political Publishing House, Ha Noi, 2001)

6. Resolution of the 8th Party Central Committee's Meeting, Session 7 (Communist Party of Vietnam, Ha Noi, 1996)

7. Raja Roy Sinh, Education for the twenty-first century: Asia-Pacific perspectives (UNESCO, Ha Noi, 1994) 